\title{
GRAZING STANDARDS IN RANGE MANAGEMENT
}

By LINCOLN ELLISON, Chief, Division of Range Management Research, Intermountain Forest and Range Experiment Station, Forest Service, U.S. Department of Agriculture, Ogden, Utah, U.S.A.

There are two axioms, or self-evident principles, that underlie grazing standards in range management: (1) A primary objective in management is normal soil stability; and (2) Grazing standards for any particular site must be based on the inherent potential of that site. The first has an ethical, the second a scientific basis.

\section{Normal Soil Stability}

Normal soil stability cannot be defined in concrete terms except for a particular site, and there are few specific sites for which we have adequate data. In general terms, let us say that, for any site supporting a soil, normal erosion is that rate of erosion which permits the constructive soil-forming processes of the site to go forward. Normal soil stability is therefore a condition represented by a net rate in which the rate of loss is no greater than the rate of increment.

The term "normal" is used, not in the sense of "prevailing" or "usual," but in the sense of the state that would exist if disturbances caused by modern man had not occurred. The term grows out of a conception of concurrent and integrated development of soil, vegetation, and topography over a long time-several thousand years probably - with no great or sudden change in over-all climate, in topography, or in species composition of plants or animals. Admittedly there have been changes during recent centuries or millennia, but the vast majority of these have been so gradual that the well-integrated ecosystem has adjusted itself to them.

As an objection to the first basic premise, one may well ask whether it is possible to graze rangeland with domestic livestock at all, especially steeply sloping land, and still maintain normal soil stability. This is an objection that cannot be answered, perhaps, except 
to say that we can surely do better in this respect than the incredible mismanagement of the past, and that, if land cannot be grazed except by materially accelerating erosion, it had better be put to some other use.

\section{Potential of the Site}

The principle that grazing standards must be based upon the potential or normal characteristics of the site, while self-evident, is not easy to implement. Determination of site potential may be extremely difficult on range lands that have been grazed a long time. However site potential is determined, it lies at the heart of management, and one's estimate of it must be as accurate as possible. Two essential characteristics of a range need to be known to define its potential.

First, normal and accelerated soil erosion need to be distinguished. These are to be inferred from the character of the soil profile and a knowledge of the processes of soil development. They can be learned if we can understand the record the ages have written in the soil profile and if we can gain a conception of normal plant cover, the obverse of normal soil stability.

The second essential characteristic is normal plant composition. "Normal" again means "undisturbed," and in this respect one's experience with the prevailing vegetation may be more misleading than helpful. Under heavy and long-continued grazing a trend toward xerophytism takes place, and because of the pervasiveness of relatively low-growing, unpalatable, and sparse vegetation that results from this process, the range ecologist may find it difficult to visualise the taller, more moisture-demanding vegetation that has been displaced.

Ideally, the way to get a picture of normal plant composition is to examine undisturbed areas in pristine condition, This is very well if they can be found, but usually such natural areas are difficult to find; and where wide-ranging wild herbivores as well as domestice livestock are in great numbers, undisturbed areas may be non-existent. Nevertheless the ecologist does what he can to reconstruct the original cover on the basis of the plant composition of the least heavily grazed range he can find and from relic plants that survive under thorny shrubs and on rock ledges least accessible to grazing animals.

There are experimental ways to determine the site potential of the range: one is to build exclosures and wait for natural recovery to occur. This is likely to be 
a long, slow process, and the device of exclosure has been handicapped in the past by our own ignorance of the complexity of the ecosystem. For example, we have built exclosures that have encouraged high "populations of rodents, so that in some instances the inside range looks worse than the outside. Or we have built exclosures too small to include relics of the pristine vegetation that might serve as a seed source for increase of those species. Or again, we have built exclosures on sites that had already deteriorated so badly by accelerated erosion that simply excluding grazing could not stop the process, and erosion has continued at a very rapid rate.

A second experimental means of evaluating site potential is to seed the range artificially, utilising combinations of different species to ascertam what the site will support when a seed source is provided. Considerable artificial revegetation, especially with exotic species, has been done on range lands in the western United States, although not particularly with the objective of defining site potential. In general, however, artificial revegetation has confirmed the results from natural areas in showing that the potential of over-grazed ranges is higher than one would have supposed simply from looking at them.

Artificial revegetation, combined with more heroic measures, may be the only way to determine the potential of sites that have lost much of their soil and that are eroding rapidly. Some sites have already deteriorated so far that they have no hope of stability if natural recovery must be depended upon; they will continue to erode until bedrock is reached, or until a very heavy erosion pavement is developed. The potential of such sites-potential for soil stability and watershed protection, if not for forage productioncan be realised only by costly artificial measures.

Where, one may ask, do the processes of primary plant succession and soil development come into the picture of site potential? Is not the true potential to be described by climax vegetation? Where a mature soil has been developed this may be so, but on partly developed soils and on deteriorated soils it is not. For purposes of management, the potentials of both vegetation and soil have to be determined by what the range manager can hope to accomplish. Primary plant succession and soil development hardly enter the picture because the range manager's life is too short. The true potential, so far as he is concerned, is not a vegetation and soil that may be realised a thousand 
or more years hence, but the most that hard work and good management can make of that site during his lifetime, or, at most, another lifetime or two beyond his own.

\section{Indicators of $R$ ange Condition and Trend (1)}

Indicators, like clues or symptoms-the three terms are synonyms-are evidence of process; All three terms refer to signs that enable the observer to tell what has occurred either in the remote or immediate past, and from this information he may infer what is occurring at present and what is likely to occur in the future.

One often hears it said that we need indicators to tell us the point at which range trend begins to decline, or the point at which improvement begins. This ability would bring us close to the millennium indeed. Unless the change is very pronounced, it is difficult to tell by a single observation of indicators what the trend is ; surely, then, it is only in the most exceptional circumstances that one may expect to pinpoint a change in trend. Even with ecological tools that are more exact than indicators we have the same difficulty; and we are obliged to face the fact that in dealing with range 'land we are dealing with something extensive and complex, where errors of observation and measurement are great.

It is well to harbour no illusions about the precision or sensitivity of indicators. They provide a rough record partly because the evidence of later events may obscure or destroy that of earlier ones. Even more important, the illegibility of the record is compounded by our own poor understanding. Many indicators depend on one's being able to distinguish between accelerated and normal erosion,' a distinction nobody has been able to make precisely. We cannot be sure, in looking at a piece of range where we see no evidence of erosion, that accelerated erosion may not be taking place. We know erosion to be accelerated only when it is so rapid as to be incongruous and manifestly cannot be normal. Such erosion indicators as we have, therefore, while they have their uses, are anything but sensitive.

There are other means of judging range condition and trend-permanent plots, chart quadrats, and repeat photographs-that are somewhat more accurate than indicators. Unfortunately these devices are not avaiiable on most range-management units. Moreover, a plot or photograph gives a record for a particular 
spot, and the only way that conclusions can be more widely applied is by observing whether the evidence that can be seen on that spot-in the form of indicators-also occurs more widely, It follows that, to get the most from indicators, the two methods need to be combined. In judging range trend there is no substitute for repeated observations of the same area, with objective descriptions of the facts and a continuity of record.

Because it is so. easy to be wrong, even with the best of methods-and being wrong is particularly easy when the range manager is anxious to detect improvement-1 think we need to allow a very generous margin of safety. This is no more than the engineer does when he sets the load limit on a bridge. After all his precise measurements of strength of materials, structural stress, and known rates of deterioration, he commonly allows a margin of safety of several hundred per cent. One engineer tells me that he uses a safety factor of four. No doubt if range managers had been in the habit of stocking ranges at one-fourth of their estimated grazing capacity, the ranges would be in better shape today. Considermg the irreparable damage that overgrazing has done, and the costs of rehabilitating broken-down range, should the range manager, whose measurements are only rough estimates, use any smaller safety factor than the engineer?

\section{Soil Indicators}

Land that supports enough vegetation to serve as range must have soil of one sort or another, and the soil itself is a valuable indicator. It serves as the base of reference for defining normal soil stability and distinguishing accelerated erosion. How closely we can determine these, and what our indicators will be, depend upon how much we know about the process of soil formation. To give an example of the type of, reasoning used, I shall refer to the soil of a subalpine herbland on the Wasatch Plateau in central Utah. (2)

Let us assume that the soil, which is 20in. deep, is 2000 years old. (The exact age doesn't matter; we could assume 1000 years or 10,000 years just as 'well. In view of the slow process of soil development in the subalpine zone, 2000 years seems a conservative guess.) In this case the normal rate of erosional loss could not be greater than lin. in 100 years. Otherwise, within the span of existence of our present climate, we, should have had no soil at all. But the erosion that is going on today is certainly much more rapid than 0.01 in. per year; conservative estimates that have been 
made from one eroding hillside in the subalpine zone of the Wasatch Plateau indicate rates of the order of 20 times as rapid.@) This. erosion must therefore be abnormally accelerated.

The indicators of accelerated erosion are simply evidence of a rate of soil loss that is obviously faster than the rate of soil formation. One hundredth part of an inch per year (and probably the average. rate of normal loss is much less) means that normal soil erosion is essentially imperceptible. Or if it is perceptible locally, in the form of washing or raindrop splash on a mound of earth excavated by a burrowing animal, it is not, as accelerated erosion commonly is, evident on a wide scale year after year. In all probability normal erosion of well-developed mountain soils is different in kind from this, as well as in amount. Probably it does not proceed mainly by surface wash, but rather by the numberless components of displacement that go into mantle creep.

- Some soil indicators relate to erosion that occurred many years ago. They are evidence of site deterioration in the past rather than of a current process. Erosion pavement and lichen lines on rocks that mark a former soil level are examples. Gullies* that incise a soil mantle, blowouts, alluvial and aeolian deposits, and soil-remnants supporting pedestalled plants, if the once-bare surfaces are now clothed with vegetation, all refer to events in the past. The plant cover, depending on its adequacy for soil protection, indicates a change for the better since the erosion indicators: were formed. If bare soil surfaces are associated with them, however, the process of deterioration is undoubtedly still going on.

Bare soil surfaces, whether in freshly cut gullies, wind-scoured depressions, or simply as subnormal plant cover at the general land-surface level, indicate, current accelerated erosion. Rill patterns cut into the soil, material displacement of soil by the trampling of animals, and of course dust clouds caused by trampling and -muddy water that originates in overland flow, all point to immediately occurring accelerated erosion.

It must be emphasised that these indicators derive their significance because they occur in association with a well-developed soil mantle. Erosion pavement may be normal on desert soils, fresh gullies and alluvial deposits may simply reflect a desert environment,

*In current A merican usage "gully" connotes accelerated erosion. It is used the normal landscape. 
and pedestalled plants or exposed roots may occur normally in environments where deep freezing of the soil is common. Furthermore, it is essential to relate, cause and effect. Fresh cutting in gullies may not indicate current overland flow, for example, but simply snowmelt; and muddy water in the creek may result from a caving bank or improper road drainage rather than from water flowing over the general land surface.

\section{Topographic Indicators}

In a sense soil indicators can also be classed as topographic indicators. Thus a gully derives its character of abnormality just as much from incising a smooth slope as from incising a well-developed soil profile; The gentle contours of the slope are fully as much the result of consistent! age-long processes as the the development of a soil profile is, and the gully is fully as indicative of interruption of the one process as of the other.

Other topographic indicators are also evidence of sudden change. in the process of land-form development. A gully that cuts through an alluvial fan and starts building a new fan beyond it, the recent cutting of such geomorphic benchmarks as' the beaches of a Pleistocene lake, or the deposition of sand and boulders upon the dark,, organic profile of a well-developed soil are examples. All suggest a change on the watershed which has suddenly increased the power of the stream, so. that processes now occur which have not occurred for many thousands of years. That they could occur naturally is possible, of course, but that they do occur naturally is highly improbable.

\section{Plant Indicators}

Like soil and topographic indicators, the significance of most plant indicators depends upon what is normal for the site in the way of cover and composition. If one has a concept of the normal, he has a basis for judgment; his judgment can. be no better than the concept he has. This has already been discussed at some length.

The range ecologist interprets trends on the basis of age classes which suggest changes in proportions of species. Or, correlating plant and soil indicators, change in amount of cover may be inferred, as for example, through occupance by young plants of formerly bared surfaces. In this case the ecologist knows that the surfaces were formerly bared because of the 
evidences of erosion on them. I wish to emphasise that he cannot see the increase in vegetation; he is obliged to infer it, which is an important distinction that is not always made in thinking about indicators. Most indicators are clues about processes that cannot themselves be observed.

Much of the use of plant indicators depends upon knowledge of the grazing habits of the animals and particularly the palatability of various plant species to them as determined by study of current utilisation, Current utilisation reflects what is happening this year rather than, like most indicators, what has happened in years past, and ideally it should give a clue to trends before they, are well advanced. If plants of a certain species are utilised so closely that they cannot repro: duce, for example, one may infer that this species will be eliminated from the stand. If another species is hardly utilised at all and is represented by many small plants as well as by older ones, its increase would seem very probable. There is no invariable relation between utilisation and range trend, however; some palatable weeds, like the common dandelion, have compensating characteristics that enable them to increase in the face of heavy utilisation.

Since animals' preferences vary, not only between kinds of animal and from one season to another, but to some extent from place to place, it is essential that grazing habits of the animals and palatabilities of the plants be assessed independently in different regions.

The hedging of shrubs by long-continued overutilisation is often a useful indicator. If the shrub is not a very palatable one, a greater degree of overgrazing would be indicated than if the shrub were highly palatable. If stems have been released above an old hedged surface, one may, infer that use has been lightened,

The accessibility of palatable plants also gives a clue to grazing pressure in past years. If palatable plants are no more common under thorny shrubs than they are in the. interspaces between shrubs, that is one thing. If they are. essentially confined as relics to the shelter of shrubs, that is quite another.

Plant vigour is often used as an "indicator." To be clear and definite we should abandon this vague - term and name the indicators that prop it up. Surely it is more meaningful to report that a shrub is severely hedged and is producing little current 'growth (for example) than that it is "low in vigour." For 
"vigour," depending on the reporter; may'refer to any of several plant characteristics-volume, height, or colour of foliage, precocity, number of flowers, success in fruiting, amount of dead material; depth of penetration or volume of roots; and perhaps others. Too often it involves as much or more subjective interpretation than objective observation. of facts, and it seldom conveys ,a clear picture,

\section{Animal Indicators}

Certain animal "weeds" have been. described as indicators of range depletion. In the south.-western United States, for example, it seems that the forage on range in fair or poor condition, as.well as the increased visibility because of short growth,. provide a more congenial habitat for jackrabbits (hares) than taller climax vegetation. Some insects, too, notably certain grasshoppers, tend to be most abundant on depleted range either because of the abundance of their particular food plants or of bare ground for oviposition, while other insects are reduced. In. other instances, fleshy rooted or bulbous plants may increase on overgrazed ranges and permit an increase of certain rodents, like pocket gophers. ${ }^{4)}$

The trouble with such indicators, no matter. how valid, is that they are secondary, themselves a result of advanced depletion. Long. before one can be sure something is wrong because animal. "weeds'! are in abnormal numbers, he probably has had advance warning through more sensitive plant and soil indicators.

Changes in weight of livestock may reflect changes in range condition sensitivity, at least in carefully controlled experimental trials. In. such trials differences in rate of gain may show up before differences in vegetation can be measured, partly, I think, because no device for measuring vegetation is anywhere nearly as accurate as livestock scales. Changes in animal weight are not practical indicators, however,. because on the open range one has nothing to compare them with such as he has in a carefully controlled experiment. Spurred on by hunger, livestock may do. well on depleted range, for many unpalatable plants are nutritious, -and the animals fill up with such forage as there is. Range can be not only depleted 'of good forage plants, but eroding very fast, and livestock may- still appear to make excellent gains. On many ranges, at least, it is only at a very advanced state of depletion that the effects on the animals are noticeable. 


\section{Factors Other-than Grazing}

It: could probably go without saying that the evaluation: of factors other than grazing is essential to understanding the influence of grazing itself. One of the most important problems in application of grazing standards is separating the effects of livestock use from the effects of other animals, whether these are ruminants, burrowing mammals, or insects, and doing this- may require a good deal of ingenuity. One needs also to be able to appraise the influence of differences in soils from place to place,, of drought or frost, of plant diseases, and of fire.

The most difficult factor to -evaluate, perhaps, is the possibility of climatic change. Whether it is a real factor or not, someone is bound is bring it up and, like any ghost, it must be laid before one can proceed with the business at hand.

I think this spectre is invoked because people are intrigued by climatic changes in the geologic past. Even -in very recent times-the period. since the last glacial maximum, which, in North America, is estimated to be about 20,000 years-we know that climates have been both colder and wetter, and warmer and drier, than they are now. More to the point, there is considerable evidence that climates during the past few centuries, in the northern hemisphere at least, have been getting a little warmer. None of the evidence-to my knowledge indicates a very material change, however, a change great enough to cause the widespread destruction of soils that we see so commonly.

\section{Summary and Conclusions}

It. would be much easier and safer to discuss grazing- standards if one were to confine himself to one certain ecosystem. Then he could stay within the definable limits of a particular climate? soil, and vegetation. But I have chosen to speak. in more general terms in order to develop general principles.

The first basic principle is that of maintaining normal soil stability or, in other words, preventing accelerated soil erosion. This, I think, we can consider ethically axiomatic to any land use.

- A second basic principle is that grazing standards must be defined in terms of the potential of the particular site under consideration, and not of any. other. In discussing the problem of Judging ecological trends in relation to grazing, we have arrived 'at two corollaries to this second proposition. 
The first is simply that the evidence we use in arriving at our judgments-the indicators of range condition and trend, the kind of utilisation we allow, and the influence of factors of the environment other than grazing-must relate to the particular ecosystem with which we are dealing. They cannot be dragged in from some other, no matter how well they may work $\mathrm{t} h \mathrm{e} r \mathrm{e}$.

The second corollary is imposed by the diversity of what we call "the range" and is implicit in our acceptance of indicators as a guide to range use. It is that the evidence we are able to find on the range itself must be our first and final authority. It does not matter what the book says is proper use. Use is proper only if we have definite evidence before our eyeswhich indicates (1) that plant cover is maintaining itself or increasing, and (2) that desirable species are maintaining themselves or increasing at the expense of less desirable ones.

These are judgments of processes, of trends, of something we cannot see but can only infer. The weakness of our judgments is that they rest upon this very slender support of inference.

I have stressed the limitations of indicators, although they are the principal tools we have, because I think we over-estimate our ability to judge condition and trend even on ranges with which we are familiar. Because of the uncertainty involved, we need to allow a generous margin for error in every judgment of range condition, trend, or grazing capacity.

\section{References}

(1) Ellison, Lincoln. Croft, A. R., and Bailey, Reed W. 1951. Indicators of Condition and Trend on High Range-Watersheds of the Intermountain Region. U.S. Dept. Agr., Agr. Handb. No. 19, 66pp.

(2) Ellison, Lincoln. Subalpine Vegetation of the Wasatch Plateau, Utah. Ecol. Monog. 24: 89-184. April 1954.

(3) Ellison, Lincoln. 1943. What is Range Improvement? Ames Forester 31: 15-22.

(4) As part of a voluminous literature, see for example: Taylor W. P., Vorhies, C. T., and Lister, P. B. The relation of jack-rabbits to grazing in southern Arizona. Jour. Forestry 33 (5): 490-498. 1935.

Smith, Charles Clinton. The effect of overgrazing and erosion upon the biota of the mixed-grass prairie of Oklahoma. Ecology 21 (3): 381-397. 1940.

Moore, A. W., and Reed, Elbert H. The Dalles pocket gopher and its infuence on forage production of Oregon mountain meadows. U.S. Dept. of Agr. Cir. No. 884, 36pp. 1951. 


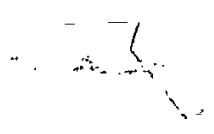

\section{DISCUSSION}

Q. What do you think about our prospects of improving our tussock country? In terms of your own experience on

A. No one needs look to the future with anything but resolution. I have great hopes that the intelligence of man will cope with some of these problems we share. We have to be realistic about it. Once you have destroyed soil, it is a poor outlook for the future. We should check soil loss as rapidly as we can and achieve some sort of stability and then make the most of the site left to us. The intelligence of man properly channelled can solve such problems. A lot has been done on difficult country already and judging by the way New Zealanders have tackled other things from Everest down, I think you can do it. 